\title{
DEL REGIONALISMO A LA VANGUARDIA EN LA NARRATIVA CENTROAMERICANA: FLAVIO HERRERA Y YOLANDA OREAMUNO
}

\author{
Francisco Rodríguez Cascante
}

\begin{abstract}
RESUMEN
En este artículo defiendo la hipótesis de que en la literatura centroamericana de la primera parte del siglo XX se establecieron dos modalidades de recepción de las vanguardias: una que desde el regionalismo construyó procedimientos de hibridación textual, y por ende, dos universos representacionales integrados. Y otra que, rechazando el regionalismo, y a partir de ese distanciamiento, asumió los mecanismos vanguardistas y procuró la autonomía del lenguaje en tanto paradigma estético. Ambos modelos escriturales constituyen el horizonte de dos formaciones textuales que diseñaron lo que se ha llamado la renovación literaria de la segunda parte del siglo XX. Ejemplifico esta discusión con el análisis comparativo de textos de Flavio Herrera y Yolanda Oreamuno; los primeros integrados en el primer modelo, mientras que los de la autora deudores del segundo.
\end{abstract}

Palabras clave: Yolanda Oreamuno, literatura centroamericana, regionalismo, vanguardia, Flavio Herrera.

\begin{abstract}
This article defends the hypothesis that Central American literature of the first part of the twentieth century established two receptive modalities for the vanguard: one from a regional perspective which constructed procedures of textual hybridization, and therefore, two integrated representational universes. And on the other hand, rejecting regionalism, and from that distancing, it assumed the mechanisms of those of the vanguard and procured the autonomy of the language in as much as the esthetic paradigm. Both writing models constitute the horizon of the two textual formations that are designed what has been called the literary rebirth of the second part of the twentieth century. I exemplify this discussion with a comparative analysis of the texts of Flavio Herrera and Yolanda Oreamuno, the most well known of this first model, whereas that of the author indebted to the second.

Key words: Yolanda Oreamuno, Costa Rican literature, regionalism, vanguard, Flavio Herrera.
\end{abstract}

Francisco Rodríguez Cascante. Catedrático en la Sede de Occidente de la Universidad de Costa Rica. subdirector del Centro de Investigación en Identidad y Cultura Latinoamericanas (CIICLA) de la Universidad de Costa Rica. Correo electrónico: rodriguezcascante@yahoo.com

Recepción: 17- 9- 2008

Aceptación: 23- 10- 2008 


\section{Introducción}

La narrativa centroamericana de finales de la primera parte del siglo XX activa, de manera polémica, el problema de la representación y su constitución en tanto producción de determinadas estrategias textuales que hacen circular los discursos literarios realistas, naturalistas y criollistas frente al paradigma de la modernización narrativa, propuesta por las vanguardias europeas. En este sentido, el regionalismo ${ }^{1}$ y su defensa de la identidad microsocial ante los avances, entendidos como homogeneizadores de la Modernidad, poco a poco se transforma y cede su predominio discursivo.

Como lo planteó Ángel Rama², el Regionalismo ha sido un esfuerzo por independizarse del pasado ibérico, lo cual desarrolló una producción cuyo afán de originalidad se basó en el deseo de distanciarse de sus relaciones fundacionales y enmarcarse en un afán internacionalista. Con base en esta preocupación surgió la idea de la representatividad: una región que procuraba distinguirse tanto por su espacio geográfico como por su distinto grado de desarrollo. Estos fenómenos, que tienen como marco histórico el período modernizador de finales del siglo XIX y principios del XX, resurgieron en la etapa de intensificación de los nacionalismos (19101940). Tanto el criollismo, como el regionalismo y el vanguardismo restauraron el principio de representatividad. Uno de los conflictos claves de la cultura latinoamericana de la primera parte del siglo XX lo planteaba la ambivalencia surgida de la necesidad de representarse con base en los marcos de la originalidad (lo particular) y su inserción en los espacios de la internacionalización mediante las apropiaciones de los modelos metropolitanos. Ésta es la manera en que se concibe la representatividad y lo particular.

Siguiendo con Rama, la polémica que mantuvieron el Vanguardismo y el Regionalismo muestra las tensiones de los procesos escriturales en su búsqueda de legitimidad representacional. En primer lugar, tanto la narrativa cosmopolita, la realista crítica y la realista social buscaron ser las fieles representantes de las identidades nacionales, aunque literariamente dependieron de modelos textuales modernos: el realismo y el naturalismo europeos, por un lado, y el realismo socialista por parte de la narrativa social.

ElRegionalismorespondió a sumomentohistórico recepcionandolainternacionalización que reclamaba una renovación para poder resguardar sus valores tradicionales. Esto significó hibridar sus estructuras literarias con las generadas por las vanguardias occidentales. Desde el punto de vista ideológico implicó la revisión e incorporación de las aportaciones de la Modernidad y, con base en ellas, se dio a la tarea de examinar los contenidos culturales regionales para componer textualidades heterogéneas capaces de seguir trasmitiendo la herencia recibida. En el ámbito centroamericano se produjeron textos que efectuaron fecundos diálogos con los de los centros de modernización. Quizá el caso paradigmático siga siendo los textos de Miguel Ángel Asturias ${ }^{3}$.

En segundo lugar, en estas relaciones habría que comprender los reclamos de autonomía de las vanguardias centroamericanas, inscritas en procesos de experimentación, búsqueda de autonomía y afán innovador, pero también como un esfuerzo de legitimación de una identidad textual propia, analizando a la misma vez las propuestas de modernización escritural propuestas por las literaturas experimentales europeas y norteamericanas. De ello da cuenta, por ejemplo, el vanguardismo nicaragüense en su distanciamiento con el modernismo dariano ${ }^{4}$.

Propongo como argumento que, en la literatura centroamericana de la primera parte del siglo $\mathrm{XX}$, en tal polémica por alcanzar la legitimidad representacional se establecieron 
dos modalidades de recepción de las vanguardias. Una que desde el regionalismo construyó procedimientos de hibridación textual, y por ende, dos universos representacionales integrados. Y otra que, rechazando completamente el Regionalismo, y a partir de esa crítica, asume los mecanismos vanguardistas y procura la autonomía del lenguaje en tanto paradigma estético.

Ambos modelos escriturales constituyen el horizonte de dos formaciones textuales que diseñaron lo que la crítica ha llamado, con diferencias en las fechas, la renovación literaria de la segunda parte del siglo $\mathrm{XX}^{5}$. Voy a ejemplificar esta tesis realizando un breve análisis comparativo entre algunos textos del guatemalteco Flavio Herrera y Yolanda Oreamuno; los primeros integrados en el primer modelo, mientras que los de la autora costarricense, deudores del segundo. Creo que es una manera de dar cuenta de un proceso fundamental en la literatura del área y, específicamente, una forma de acotar que las preocupaciones de Yolanda Oreamuno fueron el resultado de búsquedas claves de los intelectuales de la región.

\section{Flavio Herrera: De la barbarie a la subjetividad}

Desde la primera novela de Flavio Herrera, El tigre, publicada en 1932, la crítica ha develado la combinatoria de "una temática criollista con el experimentalismo formal de los vanguardistas" (Acevedo 1982: 426). Esto remite a la construcción de una arquitectura narrativa donde el fragmentarismo es el encargado de mostrar el mundo de las haciendas guatemaltecas. Más allá de verosimilizar un referente a partir de imágenes lógicas, concatenadas y realistas, la novela tiende a generar un mundo ambiguo donde la naturaleza indomable cobra carácter actancial, mientras que el mundo narrado deviene en "una especie de misticismo telúrico" (Acevedo 1982: 430).

La hacienda se constituye en el espacio sinecdótico del trópico, el cual, más que marcador geográfico frente a la ciudad, es representado como fuerza independiente y esencial del universo, cuyas regulaciones afectan la conducta humana. El breve capítulo titulado "Oración" así lo demuestra:

\footnotetext{
Trópico: ímpetu lírico de la tierra, ineluctable tercería de la locura con el amor y la muerte. En la transparencia de todos tus significados, yuxtapuestos, superpuestos, se interpreta así tu enigma: trópico: vórtice de pasión, dádiva cósmica. Oferta absoluta. Holocausto supremo. Trópico: ansia: ansia de arder. Ansia de quemarse: combustión: purificación: espiritualización (57).
}

En este mundo alucinante, en donde el tópico de la barbarie independiente y autónoma que domina al ser humano es promovido a partir de una ambivalencia esencial, se presentan dos hermanos que disputan el control del medio: Luis, el médico recién llegado y Fernando, el hermano que subsume el telurismo arrebatado del trópico. Este último termina asesinando al otro hermano, quien se convirtió en un estorbo para los desafueros del primero.

La novela se construye como rompecabezas, mediante pequeños capítulos que no se ocupan de articular una armazón lógica para el lector, quien debe imaginar y completar informaciones, tejer su interpretación de la historia y sacar luces entre el abigarrado repertorio de imágenes autónomas. Por ello se ha dicho que este texto "se adelanta a su tiempo, especialmente en el aspecto formal" (Acevedo 1982: 435).

Esta hibridación de procedimientos vanguardistas con diseños regionalistas se profundiza en la última novela de Herrera, cuyo título alude a la propuesta estética defendida: Caos, publicada en 1949. Se trata de un texto que hace dos recorridos: de la finca a la ciudad y de la exterioridad fragmentada de El tigre a la interioridad subjetiva del personaje central 
igualmente desarticulada, inestable y ambivalente, lo cual ha hecho decir a la crítica que la novela se debe ubicar en el impreciso ámbito de la "narrativa actual"'.

Desde el punto de vista estructural, la novela se divide claramente en dos sectores: los primeros 18 capítulos refieren la historia de Adolfo, un hacendado con graves problemas psicológicos y una inseguridad existencial que lo vuelve, incapaz de construir la vida que su estatus de hacendado le permite, y la perturbación y fascinación que le causa la llegada a su propiedad de Simón, un sujeto aún más perturbado con frecuentes raptos de irracionalidad:

\footnotetext{
Adolfo creyó que era una alucinación del entresueño, que era un fantasma. Hacía tiempo que vivía en un estado mórbido, en una susceptibilidad crepuscular y una aptitud para percibir en los hechos y en las cosas un aspecto recóndito, un perfil espectral y fantástico, un toque de pavoroso misterio y aquella figura alta, magra, casi esquelética vista a contra luz, le dio miedo, casi espanto (7).
}

A partir de esta presentación del personaje, el texto se mueve en el umbral del misterio y presagiando la existencia de una fuerza maligna en Simón que hace de Adolfo su protector y su víctima; el protagonista dice de Simón lo siguiente: "Con su vivir tremendo exalta en mí el caos de la tragedia vital que está engendrando y nutriendo la muerte" (36). Adolfo es un personaje inacabado, igual que Simón, cuyas historias no poseen un final conclusivo. Pero este conflicto se desarrolla en el espacio geográfico de la hacienda, igualmente considerada como el ámbito en donde se disputan fuerzas elementales de gran poder.

En segundo lugar, el otro sector textual corresponde a los últimos cinco capítulos que presentan la subjetividad de Adolfo y se distinguen de los anteriores por el predominio del monólogo interior y la cursiva. Asimismo, desaparece la hacienda como espacio geográfico para abrir campo a la exposición de la conciencia del personaje, discurso que acentúa los índices de fragmentarismo y de experimentación formal.

El desequilibrio del personaje, irresoluto en el texto, se remonta a sus primeras experiencias sexuales reprimidas por los adultos y una especie de incesto con una medio hermana del padre, lo cual lo conduce a una misoginia latente, y a rechazar la búsqueda de la felicidad por asumir una negación a la existencia mediante el criterio de la caída, "el caos de la conciencia" (187):

\footnotetext{
Otra vez, siempre a solas conmigo... con miedo a mí mismo. Con miedo a buscarme, a encontrarme, resintiendo esa impresión de caos... esa inminencia de ruina, de catástrofe, de dislocamiento elemental...

Ese perpetuo conflicto del ser... Ir siempre a ciegas tendiendo palpos para aferrarme a algo en la vida, para afirmarme... Bueno, ¿y para qué? (184).
}

La representación de la naturaleza se modifica en los textos de Flavio Herrera, para incorporar como eje de predominio la condición existencial del sujeto que la habita. Se trata de una condición de hibridación narrativa donde el modelo regionalista es modificado por medio de la recepción de la estética vanguardista; proceso que inaugura una textualización diferencial y que construyó una formación discursiva narrativo-experimental en el área.

\section{Yolanda Oreamuno: el lenguaje como conciencia}

En 1940, en el Repertorio Americano, Oreamuno publicó un artículo titulado "La vuelta a los lugares comunes", en donde expresó que el arte es un movimiento de superación de los lugares comunes conocidos, "yendo más allá de ellos y aumentándolos al propio tiempo, hasta que un nuevo movimiento más amplio, lo convierta a su vez en lugar común, sobrepasándolo" (1940: 11). Esto lo utiliza como punto de referencia para diagnosticar que 
“América demanda una higienización poética"(1940: 12), puesto lo que hacen los autores es copiar a los legitimados. Esta propuesta de limpieza estética la profundiza con mayor claridad tres años más tarde en otro texto publicado en el Repertorio: "Protesta contra el folklore"; en él arguye que

La literatura costumbrista americana, vigorizada en el dolor, plena de individualidad, es un hecho cumplido. Pero yo estimo que el clímax de saturación ha llegado y acuso a la literatura folklorista de unilateralidad. Considero que más folklore, visto como única corriente artística posible en América, significa decadentismo (1943: 84).

Ante esta sentencia cronológico-estilística, la autora propone una salida de superación del modelo estético agotado, su fórmula de asepsia: asumir una crítica a la modernidad deshumanizante, la cual contemplaría mostrar los problemas que causa la industrialización, la realidad mecanizada científica, el progreso vislumbrado como inmisericorde. Así, el artista debe desviar su mirada del campo: "La vida civilizada de nuestro Continente, (no aparte del indio, del campesino o del criollo), pero de la mano con él, es tan rica y digna de contemplarse como el panorama que ofrece el exclusivista tipicismo" (1943: 84). Esta sugerencia de salir del campo para criticar la vida de la ciudad es la opción que la modernidad excluyente requiere, y la que permitiría el impulso transformador que exige la autora. Tal ímpetu es el que necesita la vida moderna: "espero el aliento renovador de obras paraleladas con el moderno movimiento americano, para rendirles homenaje desde un porvenir literario mejor" (1943: 85).

El moderno movimiento americano tiene que ver, por un lado, con los procesos de modernización y las exclusiones que provoca, y, por otro lado, desde el punto de vista artístico, con la renovación exigida por los movimientos de vanguardia ${ }^{7}$. En estos momentos es ya un consabido hablar de la vinculación de Oreamuno con las estéticas renovadoras modernas, reconocidas por la misma autora: "Marcel Proust es mi mejor cuento de hadas" (citado por Vallbona, 1972: 41) y propagado también por la crítica (Urbano, 1968; Vallbona, 1972) y que Manuel Picado resumió en su tesis de finales de la década de 1970: "Entre las constantes de la crítica [...] [s]obresalen: influencia de los maestros de la novela contemporánea -Joyce, Mann y en especial Marcel Proust-; resonancia de su vida en su obra..." (1979: 32).

En la propuesta de Oreamuno la asunción vanguardista, que parte de un rechazo al Regionalismo, tiene como modelo estético la construcción artística en tanto espacios literarios autónomos, regidos por un uso particular del lenguaje, capaz de elaborar una representación inserta en la interioridad de la conciencia de los personajes, sin mayor referencia al mundo exterior. Este esfuerzo de autonomía ha sido leído como un trabajo por desarrollar una estética innovadora y moderna. Por ejemplo, Andreas Huyssen consideraba a finales de la década de 1980 que el objetivo de las vanguardias era construir "un arte nuevo en una sociedad diferente" (1989: 269), mientras que García Canclini sostenía que las vanguardias "hoy son vistas como la forma paradigmática de la modernidad" (1990: 42), debido a que extremaron la búsqueda de la autonomía en el arte ${ }^{8}$.

Tal exploración artística tiene en los textos de Oreamuno, obviamente, sus mayores resultados en La ruta de su evasión, publicado en 1949, la misma fecha de la novela de Herrera, Caos. Considérese el siguiente fragmento del capítulo XIII, donde se ubica el monólogo de Cristina cuando está dando a luz:

¿Pero es que no puede hacer nada de lo que deseo y sí todo lo que no deseo? ¡El dolor! Sí, ¡el dolor! Aquí está. ¿Aquí? ¡El dolor! ¿Dónde? ¿En qué parte de mi cuerpo? No podría decirlo, pero aquí está el temido, aquí está el esperado flagelándome. Yo me hago a su medida, aflojo mis músculos a su voluntad, 
a la voluntad de este dolor espantoso; doy vuelta súbitamente como si me hubiera hecho, en gracia a este intenso y rápido reatazo, liviana y frágil; me estiro, me contraigo, me distiendo, me contorsiono, y por último me relajo... (176).

La abundante presencia del monólogo incide en la configuración del texto como un universo cerrado en las conciencias de los personajes cuyo resultado es la mostración de la esfera femenina, en un discurrir cuya temporalidad es "esencialmente discursiva" (Ovares et alii 1993: 265). A diferencia del modelo asumido por Herrera, éste no representa el mundo exterior, ni siquiera el de la ciudad, sino únicamente el de la conciencia de los personajes. La novela se presenta como un encuentro de conciencias que monologan, puesto que no existe la comunicación. Tampoco se manifiesta un dialogismo, puesto que la presencia de un narrador que defiende una tesis ("la del dominio injusto del hombre sobre la mujer" (Ovares et alii 1993: 267) imposibilita la disensión en ese universo autónomo del lenguaje9 9

\section{Conclusión}

Los dos modelos estéticos defendidos por Herrera y Oreamuno configuran, para la narrativa centroamericana, lo que se ha llamado antecedentes de la nueva novela ${ }^{10}$. Considero que esta perspectiva se debe a la asunción de una historiografía de carácter lineal que atiende a las fechas y a las dimensiones biográficas, antes que a las relaciones textuales. Estimo que si los textos de Asturias, Herrera y Oreamuno poseen las "características" experimentales de esa nueva narrativa ${ }^{11}$, habría que abandonar el esencialismo lineal y considerar estos textos como integrantes de esa narrativa experimental, solo que inscritos en otro momento histórico, abandonando así la restrictiva y limitada idea de sucesión generacional y promocional y, con ello, abriendo la posibilidad de pensar estas formaciones textuales de nuestra historia literaria como regularidades discursivas que mantienen conexiones en tres niveles: relaciones entre enunciados, relaciones entre grupos de enunciados y relaciones entre enunciados o grupos de ellos y acontecimientos de órdenes distintos, que pueden ser heterogéneos y dispersos temporalmente (Foucault 1985: 51).

En mi hipótesis propuse que en los afanes por lograr una legitimidad representacional, en la literatura centroamericana de la primera parte del siglo XX, se configuraron dos modalidades de recepción de las vanguardias: una que desde la escritura regionalista se hibridó con la estética moderna y otra que, partiendo de una crítica radical del Regionalismo, asumió los procedimientos vanguardistas y modelizó la autonomía artística como universo particular del lenguaje. De ambos proyectos son ejemplos las escrituras de Flavio Herrera y Yolanda Oreamuno, propuestas estéticas que configuraron caminos claves en la búsqueda de nuestra modernidad literaria.

\section{Notas}

1. El regionalismo, como lo define José Miguel Oviedo, es un modelo estético que alude a un "elemento clave: el paisaje local, la tipicidad de la naturaleza y su influjo sobres sus personajes (indios, mestizos, gauchos, llaneros, campesinos" (2001, 201). Por otra parte, "su conflicto básico es el del hombre en pugna con un medio físico indómito y fascinante, un mundo salvaje que trata de someter por un esfuerzo de su voluntad" (226).

2. Véase el capítulo 1 de su Transculturación narrativa en América Latina. 
3. Dante Liano afirma que Asturias "ofrece una visión total, que parte de la problemática nacional para darnos una interpretación general del mundo. La obra de Asturias alcanza dimensión universal precisamente porque el escritor observa de manera prolija cada espacio de su provincia natal, bebe de sus fuentes más recónditas y antiguas sin dejar de estar atento al devenir que le es contemporáneo” (1997, 145).

4. En 1931 Pablo Antonio Cuadra señaló en un artículo titulado "Dos perspectivas" que el Movimiento de Vanguardia estaba dinamizado por dos fuerzas: "Una: Nacionalizar. Dos: Hacer un empuje de reacción contra las roídas rutas del siglo XIX. Mostrar una literatura nueva (ya mundial). Regar su semilla." (1991, 214).

5. Véase al respecto, el artículo de Ramón Luis Acevedo. "Orígenes de la nueva novela centroamericana (1968-1980)" y el fundamental libro de Seymour Menton. Historia crítica de la novela guatemalteca, capítulo 9.

6. Indica Ramón Luis Acevedo: “Caos es una novela psicológica donde el autor se concentra en el análisis de un personaje desquiciado y angustiado. Como tal, rebasa por completo el criollismo y entra de lleno en la novelística actual sobre todo por la técnica experimental que el autor emplea para captar la interioridad atormentada del personaje" (1982: 441).

7. Esta posición era un consenso en la época. Otro destacado intelectual como Luis Cardoza y Aragón opinaba que ser moderno implicaba abandonar el regionalismo, por localista y "pintoresco", para producir una literatura lo más alejada posible del realismo, la que debía dialogar con los cánones estéticos legitimados por los centros de modernización internacional. Así, los principios renovadores de las vanguardias se convirtieron para él tanto en sinónimo de norma literaria como de modernidad cultural. Véase: Cardoza y Aragón. Miguel Ángel Asturias, casi novela (1991).

8. Reafirma esta posición el autor indicando que: “a veces intentaron combinarla con otros movimientos de la modernidad -especialmente la renovación y la democratización. Sus desgarramientos, sus conflictivas relaciones con movimientos sociales y políticos, sus fracasos colectivos y personales, pueden ser leídos como manifestaciones exasperadas de las contradicciones entre los proyectos modernos" $(1990,42)$.

9. Manuel Picado ha señalado la presencia dominante de este narrador: "La omnisciencia del narrador y su figura tan perfilada ocasionan una fuerte ingerencia en el mundo de la ficción, lo cual hace que lo narrado se condicione a premisas muchas veces ampliamente explicitadas. El mundo narrativo, en la medida en que existe, está sometido a pensamientos y condiciones externas expuestas por el hablante básico. La actitud del narrador más que fidelidad a la mostración de mundo, es una actitud demostrativa. El mundo de la narración se da entonces en marcos de referencia, con el problema de que muchas veces esos marcos son bastante dudosos en su enunciación" (1979: 49).

10. Indica Ramón Luis Acevedo: “No obstante, los casos anteriores [incluye a Herrera y a Oreamuno], incluso el de Asturias, son más bien elementos aislados en su momento, manifestaciones individuales que no tienen continuación inmediata y que no representan la modalidad dominante de novelar en la región. Sólo a partir de la década del setenta, tras el fecundo impacto del "Boom", se produce en Centroamérica con suficiente intensidad y calidad lo que podríamos llamar una nueva narrativa" (1994: 117).

11. Dice Acevedo: "Como características de la nueva novela se han señalado, entre otras, las siguientes: experimentación técnica, que se vale de recursos como el fluir de conciencia, la fragmentación y dislocación del tiempo, el perspectivismo y la multiplicidad de voces narrativas; apertura hacia el lector y la exigencia de su activa colaboración; humor, ambigüedad y sentido lúdico; la intención totalizadora 
que estimula la inclusión de dimensiones antes desterradas o soslayadas, como el mito, la fantasía y los niveles profundos de la psiquis colectiva e individual; y la preocupación y elaboración del lenguaje como resultado de la conciencia de la autonomía del texto de ficción, concebido primordialmente como creación verbal y no mero reflejo de la realidad exterior a él. Esto último nos lleva a la 'metaficción' o a la novela que manifiesta internamente su conciencia de la propia literariedad" (1994: 113).

\section{Bibliografía}

Acevedo, Ramón Luis.1982 La novela centroamericana. Río Piedras, Puerto Rico: Editorial Universitaria.

1994. "Orígenes de la nueva novela centroamericana (1968-1980)". Revista La Torre. 7 (29): 113- 48.

Cardoza y Aragón, Luis. 1991. Miguel Ángel Asturias, casi novela. México: Ediciones Era.

Cuadra, Pablo Antonio. 1991. "Dos perspectivas". Las vanguardias latinoamericanas. Jorge Schwartz (ed.). Madrid: Cátedra, 214- 215.

Foucault, Michel. 1985. La arqueología del saber. México, D.F.: Siglo Veintiuno Editores.

García Canclini, Néstor. 1990. Culturas híbridas. Estrategias para entrar y salir de la modernidad. México: Editorial Grijalbo.

Herrera, Flavio. 1949. Caos. Guatemala: Editorial Universitaria.

1984. El tigre. Guatemala: Editorial Universitaria.

Huyssen, Andreas. 1989. "Guía del posmodernismo". El debate modernidad-posmodernidad. Nicolás Casullo (ed.). Buenos Aires: Puntosur Editores, 266-318.

Liano, Dante. 1997. Visión crítica de la literatura guatemalteca. Guatemala: Editorial Universitaria.

Menton, Seymour. 1985. Historia crítica de la novela guatemalteca. Guatemala: Editorial Universitaria de Guatemala.

Oreamuno, Yolanda. 1940. "La vuelta a los lugares comunes". Repertorio Americano. 37 (1): 11-13.

1943. "Protesta contra el folklore". Repertorio Americano. 40 (5): 84- 85.

1980. La ruta de su evasión. $4^{\mathrm{a}}$ ed. San José: EDUCA. 
Ovares, Flora et alii. 1993. La casa paterna. Escritura y nación en Costa Rica. San José, Costa Rica: Editorial de la Universidad de Costa Rica.

Oviedo, José Miguel. 2001. Historia de la literatura hispanoamericana. Tomo 3. Madrid: Alianza Editorial.

Picado Gómez, Manuel. 1979. “La ruta de su evasión” de Yolanda Oreamuno. San José, Costa Rica: Editorial de la Universidad de Costa Rica.

Rama, Ángel. 1985. Transculturación narrativa en América Latina. México: Siglo Veintiuno.

Urbano, Victoria. 1968. Una escritora costarricense: Yolanda Oreamuno. Madrid: Ediciones Castilla de Oro.

Vallbona, Rima de. 1972. Yolanda Oreamuno. San José: Publicaciones del Ministerio de Cultura, Juventud y Deportes. 